\title{
Femtosecond laser interaction with energetic materials
}

\author{
E. Roos, J. Benterou, R. Lee, F. Roeske and B. \\ Stuart
}

This article was submitted to SPIE's International Symposium High-Power Laser Ablation 2002 Taos, NM, April 24, 2002

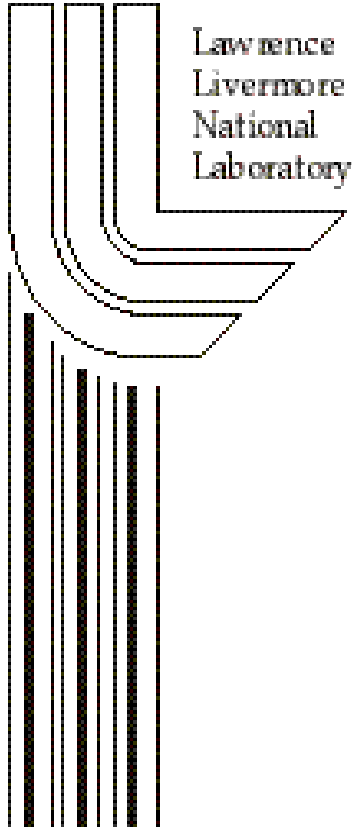

March 25, 2002 


\section{DISCLAIMER}

This document was prepared as an account of work sponsored by an agency of the United States Government. Neither the United States Government nor the University of California nor any of their employees, makes any warranty, express or implied, or assumes any legal liability or responsibility for the accuracy, completeness, or usefulness of any information, apparatus, product, or process disclosed, or represents that its use would not infringe privately owned rights. Reference herein to any specific commercial product, process, or service by trade name, trademark, manufacturer, or otherwise, does not necessarily constitute or imply its endorsement, recommendation, or favoring by the United States Government or the University of California. The views and opinions of authors expressed herein do not necessarily state or reflect those of the United States Government or the University of California, and shall not be used for advertising or product endorsement purposes.

This is a preprint of a paper intended for publication in a journal or proceedings. Since changes may be made before publication, this preprint is made available with the understanding that it will not be cited or reproduced without the permission of the author.

This report has been reproduced directly from the best available copy.

Available to DOE and DOE contractors from the

Office of Scientific and Technical Information

P.O. Box 62, Oak Ridge, TN 37831

Prices available from (423) 576-8401

http:/ / apollo.osti.gov/bridge/

Available to the public from the National Technical Information Service

U.S. Department of Commerce 5285 Port Royal Rd., Springfield, VA 22161

http://www.ntis.gov/

OR

Lawrence Livermore National Laboratory Technical Information Department's Digital Library http:/ /www.llnl.gov/tid/Library.html 


\title{
Femtosecond laser interaction with energetic materials
}

\author{
E. Roos, J Benterou, R. Lee, F. Roeske, and B. Stuart \\ Lawrence Livermore National Laboratory, P. O. Box 808, Livermore, CA 94550 USA \\ (925) 423-2175, E-Mail roos2@llnl.gov
}

\begin{abstract}
Femtosecond laser ablation shows promise in machining energetic materials into desired shapes with minimal thermal and mechanical effects to the remaining material. We will discuss the physical effects associated with machining energetic materials and assemblies containing energetic materials, based on experimental results.

Interaction of ultra-short laser pulses with matter will produce high temperature plasma at high-pressure which results in the ablation of material. In the case of energetic material, which includes high explosives, propellants and pyrotechnics, this ablation process must be accomplished without coupling energy into the energetic material. Experiments were conducted in order to characterize and better understand the phenomena of femtosecond laser pulse ablation on a variety of explosives and propellants. Experimental data will be presented for laser fluence thresholds, machining rates, cutting depths and surface quality of the cuts.
\end{abstract}

Keywords: Laser ablations, femtosecond lasers, explosives and propellants

\section{Introduction}

Laser machining of energetic materials and assemblies containing energetic materials is of interest to the scientific and engineering community. The application of laser machining of energetic materials is for the fabrication of new components for test or production and for the disassembly of existing ordnance systems for surveillance or dismantlement. Energetic materials are defined as chemical compounds, which contain both fuel and oxidizer, which react in a short time frame and release a pulse of energy. Examples of energetic materials are high explosives, propellants and pyrotechnics. Energetic materials are thermally, mechanically, and in some case electrostatic, sensitive. Some by-products may be environmentally sensitive. In some cases, material properties have changed with age affecting the sensitive and stability of the energetic material.

Ablation of energetic materials by femtosecond laser pulses is an attractive alternative to conventional machining [1,2]. Absorption of these ultra-short pulses occurs on such a short time scale that the material is ablated with virtually no heat transfer to the surrounding material [3] resulting in a "cold" laser cutting process and hence, a safe process. In contrast, laser cutting techniques that use laser pulses longer than $\sim 10 \mathrm{ps}$, melt the material and some of the material is vaporized. The rest of the material is blown away with an air stream or re-condenses. There is an amount of slag and re-condensed material deposited on the surface of the material being cut. This deposited material may result in contamination of the starting material. This paper will also discuss femtosecond laser machining of assemblies containing energetic materials, where the energetic materials is in direct contact with metals and dielectrics.

\section{Experimental samples and set-up}

Several energetic materials were chosen for machining with the femtosecond laser. In the high explosive (HE) category there are several ways the material is configured such as pressed, melt cased and plastic bonded explosives (PBX). For propellants we consider two types: double base and composite materials. To date we have not fs laser cut pyrotechnic material. Table I is a list of some key properties of typical high explosives. As this table shows, HE has a poor thermal conductivity, therefore heat that is coupled into the material will not be dissipated quickly. Table II lists the materials we machined with the femtosecond laser, which will be presented in this paper. 


\begin{tabular}{|l|l|l|l|l|}
\hline Energetic material & LX-14 & Comp B & Lead Azide & PETN \\
\hline Color & $\begin{array}{l}\text { White/Blu } \\
\text { e }\end{array}$ & Brown & White & White \\
\hline Physical state & Solid & Putty-like solid & Solid & solid \\
\hline Density $\left(\mathrm{g} / \mathrm{cm}^{3}\right)$ & 1.83 & $1.58-1.62$ & 4.3 & 1.78 \\
\hline Refractive index & $1.578-1.6$ & $1.578-1.6$ & 0 & 1.551 \\
\hline Melting point $\left({ }^{\circ} \mathrm{C}\right)$ & 270 & $79-80$ & $\begin{array}{l}\text { Decomposition } \\
345\end{array}$ & 140 \\
\hline $\begin{array}{l}\text { Thermal conductivity }\left(10^{-4}\right. \\
\left.\text { cal/cm-sec- }-{ }^{\circ} \mathrm{C}\right)\end{array}$ & 10.42 & 5.23 & & \\
\hline $\begin{array}{l}\text { Coefficient of thermal } \\
\text { expansion }\left(\mu \mathrm{cm} / \mathrm{cm}^{\circ}{ }^{\circ} \mathrm{C}\right)\end{array}$ & 55.8 & 97.5 & $76.9,3.4, \& 18.3$ & 76.5 \\
\hline
\end{tabular}

Table I Mechanical properties of HE

\begin{tabular}{|c|c|c|c|c|}
\hline Material ID & Description & $\begin{array}{l}\text { Energetic } \\
\text { Material }\end{array}$ & Comments & Results \\
\hline \multicolumn{5}{|l|}{$\begin{array}{l}\text { High } \\
\text { Explosives }\end{array}$} \\
\hline PBX-9407 & RDX/binder & $\mathrm{HE}$ & PBX & $\begin{array}{l}\text { Cut easily at low laser } \\
\text { fluence }\end{array}$ \\
\hline LX-14 & HMX/binder & $\mathrm{HE}$ & PBX & $\begin{array}{l}\text { Cut easily at low laser } \\
\text { fluence }\end{array}$ \\
\hline LX-15 & HNS/binder & $\mathrm{HE}$ & PBX & $\begin{array}{l}\text { Cut with some minor } \\
\text { problems }\end{array}$ \\
\hline LX-16 & PETN/binder & $\mathrm{HE}$ & PBX & $\begin{array}{l}\text { Cut easily at low laser } \\
\text { power }\end{array}$ \\
\hline $\mathrm{LX}-17$ & TATB/binder & $\mathrm{HE}$ & PBX & $\begin{array}{l}\text { Cut easily at low laser } \\
\text { fluence }\end{array}$ \\
\hline TNT & TNT & $\mathrm{HE}$ & Melt cast & $\begin{array}{l}\text { Cut easily, low laser } \\
\text { power, melting }\end{array}$ \\
\hline Comp B & RDX and TNT & $\mathrm{HE}$ & $\begin{array}{l}\text { Pressed or melt } \\
\text { cast }\end{array}$ & $\begin{array}{l}\text { Cut easily at low laser } \\
\text { power, melting }\end{array}$ \\
\hline \multicolumn{5}{|l|}{ Detonators } \\
\hline & PETN & $\begin{array}{l}\text { Secondary } \\
\text { explosive }\end{array}$ & Secondary HE & $\begin{array}{l}\text { Cut easily at low laser } \\
\text { fluence }\end{array}$ \\
\hline & Lead Azide & $\begin{array}{l}\text { Primary } \\
\text { explosive }\end{array}$ & Primary HE & $\begin{array}{l}\text { Material detonates when } \\
\text { ablated by fs laser }\end{array}$ \\
\hline & Lead Styphnate & $\begin{array}{l}\text { Primary } \\
\text { explosive }\end{array}$ & Primary HE & $\begin{array}{l}\text { Material detonates when } \\
\text { ablated by fs laser }\end{array}$ \\
\hline \multicolumn{5}{|l|}{ Propellants } \\
\hline PS-1 & $\begin{array}{l}\text { AP and } \\
\text { Aluminum }\end{array}$ & $\begin{array}{l}\text { Composite } \\
\text { propellant }\end{array}$ & Rocket propellant & $\begin{array}{l}\text { Cut easily at low laser } \\
\text { power, thermally } \\
\text { sensitive }\end{array}$ \\
\hline HPC-45 & $\begin{array}{l}\text { Nitrocellulose- } \\
\text { Nitroglycerine }\end{array}$ & $\begin{array}{l}\text { Double base } \\
\text { propellant }\end{array}$ & Gun propellant & $\begin{array}{l}\text { Cut easily at low laser } \\
\text { power, thermally } \\
\text { sensitive }\end{array}$ \\
\hline
\end{tabular}

Table II - Is a list of the energetic materials, which were laser, cut 
Laser ablation experiments were preformed on energetic materials with a Lawrence-Livermore-NationalLaboratory-developed, breadboard femtosecond laser. TABLES III gives specification for the LLNL laser and Figure I shows a cartoon and layout drawing of the laser of the femtosecond laser.

\begin{tabular}{|l|l|}
\hline Specification & Value \\
\hline Laser medium & Ti:Sapphire \\
\hline Optical wave length & $810 \mathrm{~nm}$ \\
\hline Pulse rate & $3500 \mathrm{pps}$ \\
\hline Pulse width & $150 \mathrm{fs}$ \\
\hline Average laser power & $3.5 \mathrm{watts}$ \\
\hline Laser energy & $1 \mathrm{mj} / \mathrm{pules}$ \\
\hline Beam diameter & $12 \mathrm{~mm}$ \\
\hline
\end{tabular}

Table III - Laser performance specification
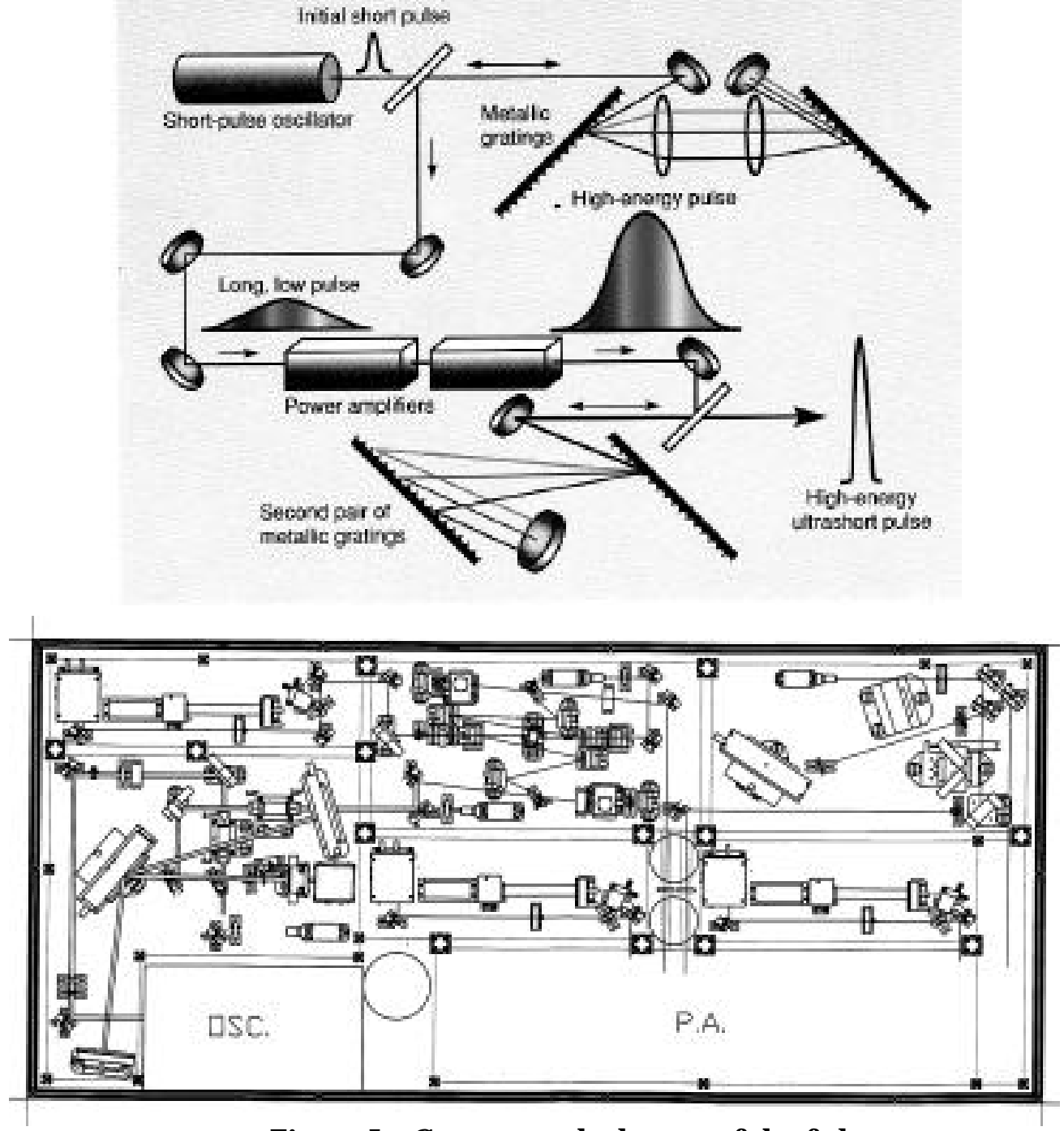

Figure I - Cartoon and a layout of the fs laser 
Laser cutting of energetic material was performed in vacuum or at atmospheric pressure within a tank. The tank was designed to contain the pressure pulse, fragments, and heat resulting from a detonation or deflagration. Figure II is a photo of the experimental set-up of the cutting activity. The tank is equipped with several CCD cameras and an optical spectrometer monitoring the optical emission of the sample being cut. The energetic material test samples were mounted on a 4-axis motion control system, which moves the energetic material sample with respect to the laser beam. The $12 \mathrm{~mm}$ diameter laser beam is focused to the desired beam diameter with a single lens, which will produce the desired laser fluence. There is an optional laser beam trepanning system, which produces a circlecutting pattern.

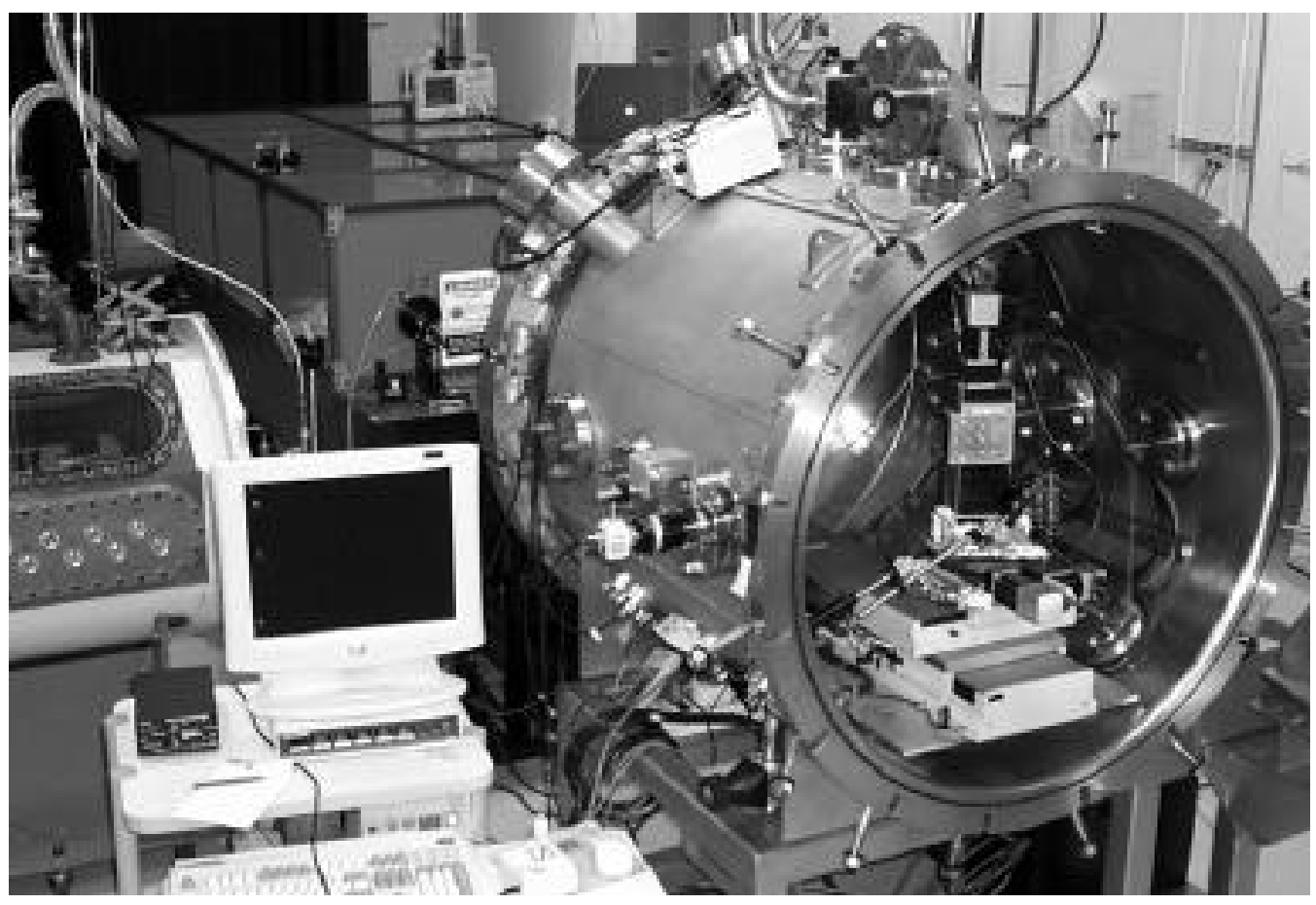

Figure II - Photo of the experimental set-up

\section{Experimental results}

Having a laboratory with a femtosecond laser, containment tank and monitor and controls system, we are able to safely perform laser ablation on energetic materials. The objective of the experiments is to obtain quantitative data in the following:

- Establish optimum cutting parameters for energetic materials and ordnance systems.

- Establish machining rates for various materials and process.

- Find safety limits for various explosives, which allow us to safely cut into energetic material without detonation or deflagration.

- Establish size, material or geometry limits.

- Physical changes in the material, such as surface quality, particle size, and loss of binder and changes in density or formation of voids.

- Have the energetic properties of the material been affected?

We have established the cutting parameters for all energetic materials named in table 1 . The key parameter, laser fluence, was found to be optimal at 1 to $4 \mathrm{~J} / \mathrm{cm}^{2}$ for the energetic materials listed in table I. This is in agreement with laser ablation of dielectric materials [3, $4 \& 5]$. Laser fluence above these levels dose not increase cutting rates and roughens the laser ablated surface, which may result in heating 
the high explosives. Several experiments were performed to determine the effects of cutting deeply into energetic material.

\section{High explosives}

The first experiments were to cut slots 6 to $12 \mathrm{~mm}$ deep through high explosive material, clean up the laser cut and inspect the HE material. Figure 3 shows magnified and enhanced optical photographs of three materials, LX-14, LX-17 and CompB. These photographs show that the size and shape of the crystals of high explosive have not been modified, the presence of the binder, and the absence of voids. The optical inspection is in agreement with standard material showing that the crystal size and presence of binder and density of material has not noticeably changed.

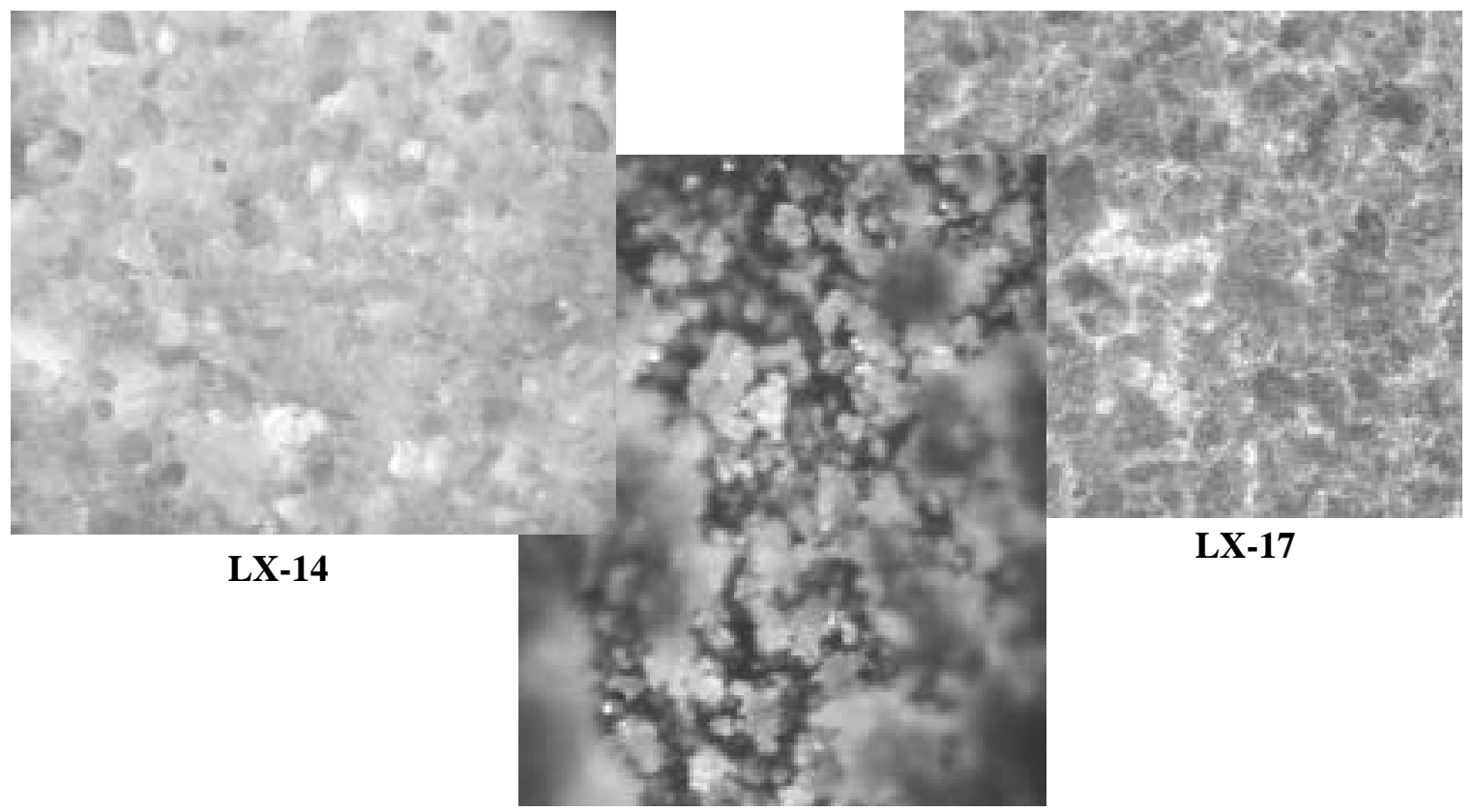

Comp B

Figure 3 - Photo of femtosecond-laser cut surfaces of high explosive material

Femtosecond laser cutting is advertised as cold cutting, meaning that there is little heat deposited in the ablation process. This is true but when cutting deeply into material, the laser beam may dwell in a position for a period of time or large angle scattering may reflected and couple some of the laser energy into the material being ablated. Figure 4 shows photographs of high explosives cut at a laser fluence of $\sim 2 \mathrm{~J} / \mathrm{cm}^{2}$ and a laser beam movement of $4 \mathrm{~mm} / \mathrm{min}$. Under these conditions there were around 1000 laser pulses in a displacement of one beam diameter. The Comp B, a material with a melting point of $80^{\circ} \mathrm{C}$, shows obvious evidence of melting by the cutting operation. The LX-14 also shows evidence of melting. LX-14 is 95\% HMX and 5\% estane. HMX melts at $270^{\circ} \mathrm{C}$ and then goes exothermic, but the binder can melt and flow. We have concluded for safety and efficiency, coupling of laser energy into the high explosives is unacceptable, therefore we need to find an acceptable cutting process. In Figure 5 we show the results of cutting performed as in Figure 4 but, the laser beam motion was increased to $40 \mathrm{~mm} / \mathrm{min}$ and the number of passes was increased by 10 times. Therefore the total number of laser pulses remain the same. Figure 5 shows no evidence of melting.

Most laser ablation is performed in a vacuum or in controlled atmospheric and conditions. The effects of laser ablation in non-vacuum conditions can noticeably affect the results of laser ablation [6]. All of the laser ablation presented in this paper was performed in air and under standard pressure and temperature conditions. Effects due to ionization of the gas medium, including plasma defocusing, self-phase modulation and cooling of the plasma are 
present in an air atmosphere. Femtosecond laser ablation of Comp B in a vacuum did not display evidence of melting. It is our belief that the melting occurs by the heating of the air in front of the energetic materials. The laser beam is defocused and distorted, producing an increased spot size resulting in low laser fluence and coupling of laser energy into the energetic materials.

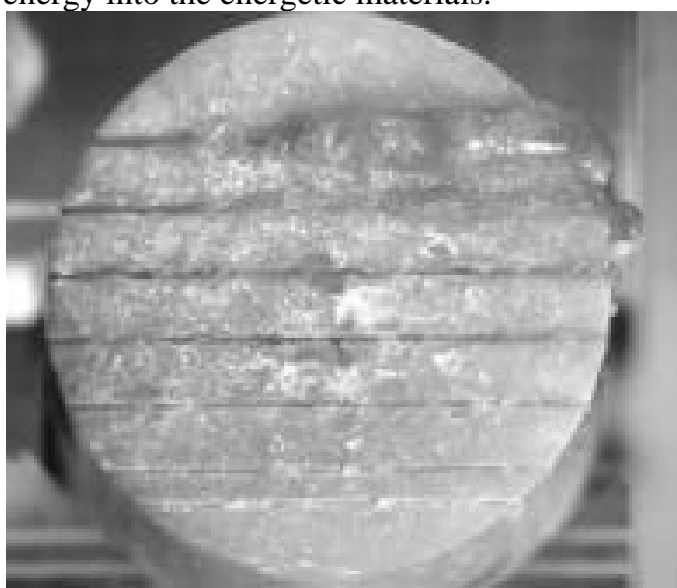

Comp B

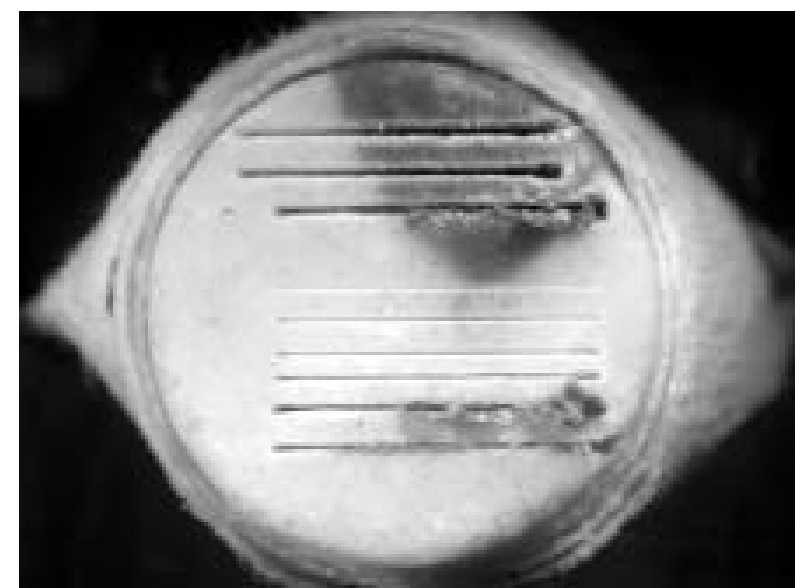

LX-14

Figure 4 - Photo of a cut with a fs laser of high explosive and the material melts

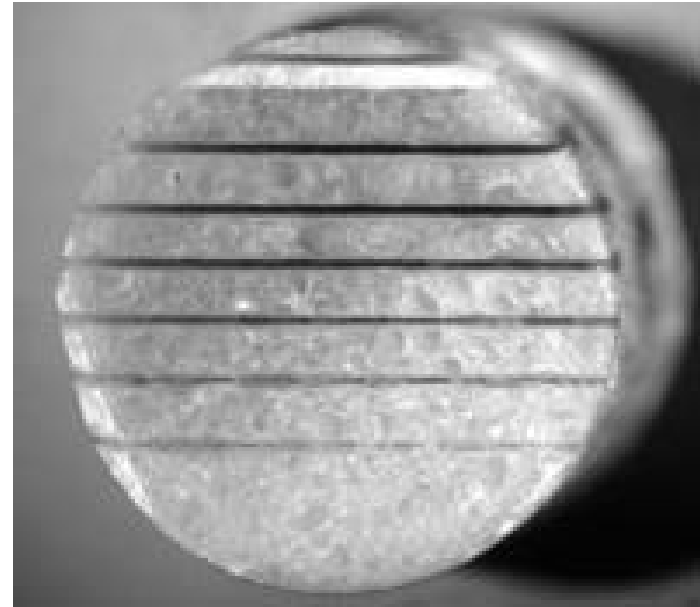

LX-14 without heating

Figure 5 - Photo of a cut with a fs laser of high explosive without melting

\section{Detonators}

Detonators used in explosive systems are a sub-system of the initiation system, which consists of a firing system, a detonator material and a booster material. The initiation system varies in design from low-voltage hot wire systems to exploding bridge wire (EBW) and slapper systems. The detonator high explosive is of two types, primary and secondary high explosives. Booster material is high explosive used to apply additional explosive energy used to detonate the main explosive charge. The first detonator experiment was the sectioning a hemispherical (hemi) detonator. The hemi detonator had a 0.5 -inch diameter and was enclosed in aluminum housing with a plastic base where the bridgewire is located. Figure 6 is a graphic of the detonator assembly. The thin aluminum shell was cut off the plastic header with the fs laser exposing the PBX-9407. The PBX-9407 was ablated exposing the PETN detonator material. Figure 7 shows hemi detonators, which were fs laser ablated to 5 different thickness of HE. The HE column varied from $0.75 \mathrm{~mm}$ to $4.0 \mathrm{~mm}$. Close inspection of the surface quality of the PBX-9407 and PETN 
show that the femtosecond laser cutting process did not modify the HE material properties. This is a noteworthy accomplishment, since the PETN is pressed to half density, making the material sensitive to external energy sources. For example the PETN can easily fall out or its density can be changed by heat or pressure.

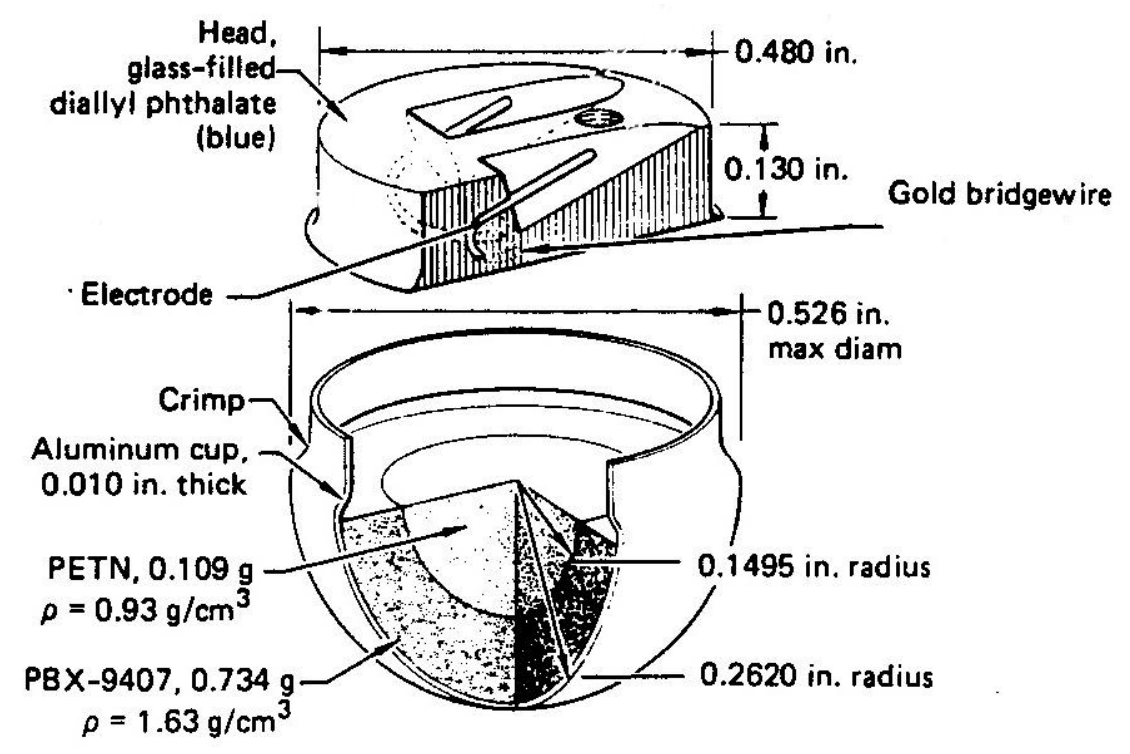

Figure 6 - Drawing of the detonator assemble

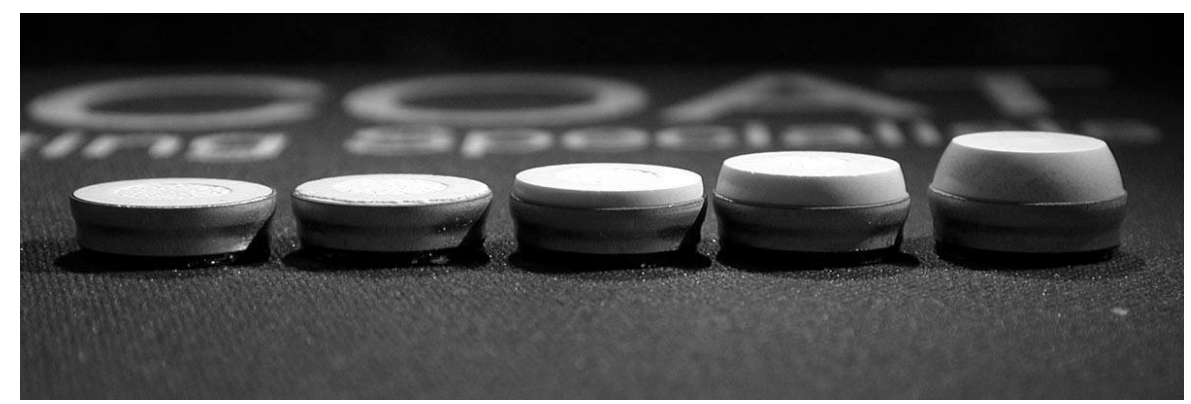

Side view of detonators

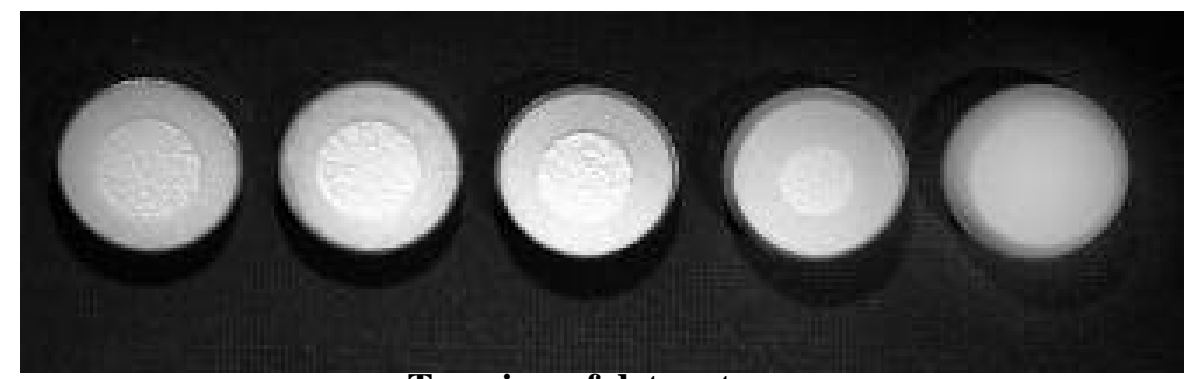

Top view of detonators

Figure 7 - Hemispherical detonators cut by femtosecond laser

In another experıment on detonators, laser ablatıon was attempted on assemblies containing lead azide and lead styphnate. The lead azide and lead styphnate were pressed into stainless steel cylinders enclosed on all sides but one. When we attempted to cut through the SS into the HE, both lead azide and 
lead styphnate detonated. Detonation occurs immediately when the beam impinges directly on the HE. We were successful in cutting through the SS to within less than $1 \mathrm{~mm}$ on the lead azide or lead styphnate without detonation. This experiment was performed to determine whether the source of the detonation was charge produced in the cutting process or hot metal particles from the cutting process. At present we are leaning towards the hot metal particles.

\section{Propellant}

Propellants are used in guns, air bags, fireworks, and missiles. Two types of propellants were chosen; a composite propellant material called PS- 1 and double base material called HPT-45. The PS- 1 has a fuel of aluminum and an oxidizer of ammonium perchlorate, while the HPC-45 is a nitrocellulose-nitroglycerine based material.

The first laser ablation of propellant was performed on the PS-1. We quickly learned that any heat and or spark source ignited the propellant. The laser beam heating of the surface and a sparks from the laser via air breakdown are potential ignition sources. After several attempts we were able to cut holes, slots and lines in PS-1 without ignition of the propellant. We then wrapped the PS-1 is a triple thickness of aluminum foil and was able to cut though the $\mathrm{Al}$ into the propellant without ignition. It should be noted that throwing hot metal particles onto the propellant often ignites propellants. Figure 8 shows a photo of PS-1 ablated with a femtosecond laser.

We preformed similar experiments on the HPC-45 and were able to ablate the gun propellant without initiation.

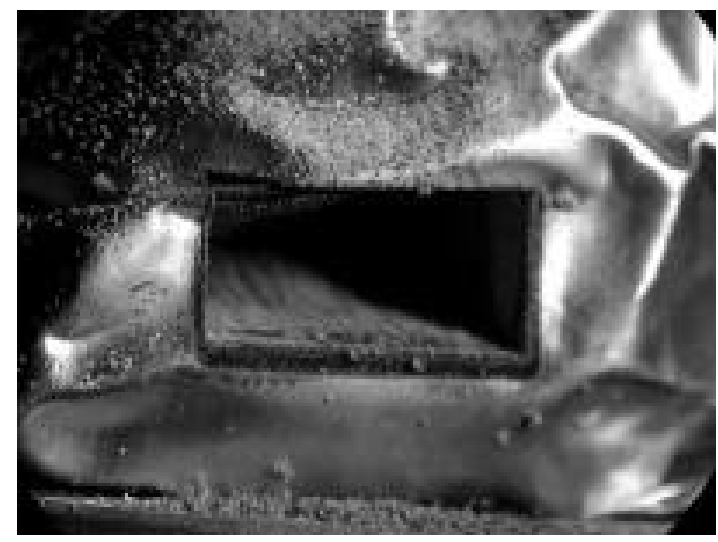

Propellant with an Al cover

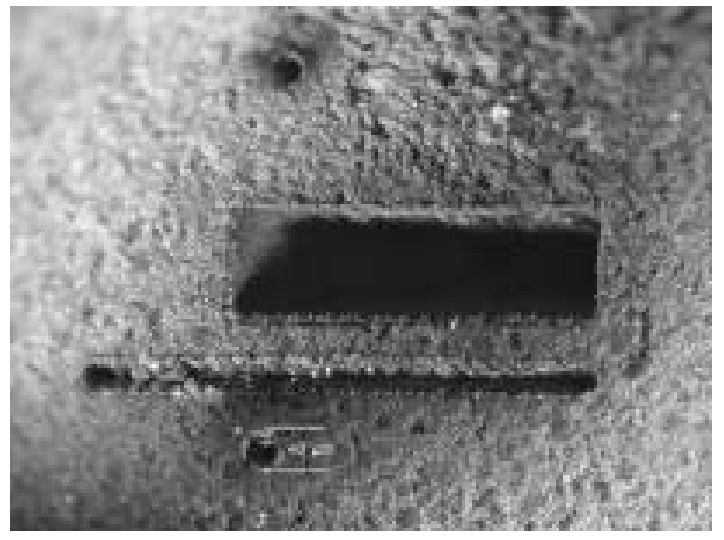

Propellant with laser cut with Holes, lines and slots

Figure 8 - PS-1 rocket propellant cut with a femtosecond laser 


\section{Conclusions}

We have shown that the application of femtosecond laser ablation of energetic materials is promising. The ultrashort pulse lasers can safely ablate energetic materials without effecting the remaining material. This application is a useful tool for demilitarization, surveillance and the creation of new ordnance components. Femtosecond laser cutting is expected to be a technique that can be used to disassemble munitions that are difficult to disassemble by other means without safety concerns or the generation of an unacceptable waste stream. The clean, precision cut made by the femtosecond laser makes it an attractive candidate for many surveillance operations. Finally, novel new shapes of explosives, which can be cut with relative ease with the femtosecond laser, will make possible the development of new energetic components.

The work to date has proven the viability of the ultra-short, high-powered laser-cutting technique for cutting energetic materials. The femtosecond laser is located near a energetic material containment tank capable of handling $10 \mathrm{~kg}$, which allows for the cutting of large HE assemblies and actual ordnance. Thus the femtosecond lab will serve not only to develop the science and applications of femtosecond cutting of explosives but also to serve as a testbed for full-scale mock-up or actual ordinance items.

\section{Acknowledgment}

We acknowledge the support of Dennis Baum and Randy Simpson. Jerry Benterou with the assistance of Don Burns and Kou Moua did the experimental work. The University of California, Lawrence Livermore National Laboratory under contract No.W-7405-Eng-48, performed this work under the auspices of the U.S. Department of Energy.

\section{Reference}

1. F. Roeske, J. Armstrong, P. Banks, M. Feit, R. Lee, M. Perry and B. Stuart, "Laser Cutting of Pressed Explosives", Energetic Materials, Production, Processing and Characterization, Germany: Fraunhofer-Institut fur Chemische Technologie, 1998, pp 104-1 - 104-14.

2. F Roeske, P. Banks, J. Armstrong, M. Feit, R. Lee, M. Perry, and B.. Stuart, "Laser Cutting of Pressed Explosives”, Proceedings of 1998 Life Cycles of Energetic Materials, 1998, pp. 344-347.

3. X. Lin, D. Du and G. Mourou, "Laser ablation and micro-machining with Ultrashort laser pulses", IEEE J. of Quantum Electronics, Vol. 33, No. 10, Oct. 97, pp 1706-1716

4. D. Ashkenasi, G. Herbst, A. Rosenfield, H. Varel, M. Lorenz, and R. Stoian, "Laser ablation and structuring of transparent materials with ultrashort pulse lasers", Proceeding of SPIE Vol. 3343, pp 400-410

5. P. Banks, B. Stuart, A. Komashko, and M. Feit. A. Rubenchik, and M. Perry, "Femtosecond laser materials processing", Proceedings of SPIE, Vol. 3343

6. J. Sun and J. Longtin, "Inert gas beam delivery for ultrafast laser micromachining in ambient pressure", Journal of Applied Physics, Vol. 89 number 12, June 15, 2001, pp 8219-8224 